The Geneva Papers on Risk and Insurance, 20 (No. 76, July 1995), 336-347

\title{
The Environmental Insurance Markets in the U.S. and Western Europe: A U.S. Underwriter's Observations
}

by William Kronenberg, III*

\section{Introduction}

When one reflects upon today's marketplace for environmental insurance there is an eerie feeling of somehow having stepped into H.G. Wells' time machine and returned to the early 1980's. In the U.S., there is an unpleasant sense of deja vu. In Western Europe, one observes a fledgling industry boldly responding to today's environmental problems but possibly heading for trouble if, as appears to be the case in some quarters, it does not learn from the past mistakes of its U.S. cousin.

In the U.S., there are endless press releases about the «environmental insurance company du jour» and it is difficult to remember that it is 1995 and not 1983, when over two dozen companies actively but briefly pursued environmental insurance. In Europe, one puzzles over the underwriting premise that prices environmental risk at levels that would not even pay the engineering costs of a good site survey.

Listening to the latest environmental insurance underwriting experts in both places expound upon their newfound ability to profitably underwrite this class of business without lengthy applications or expensive risk assessment surveys, one must double check the calendar. Wasn't it just 12 years ago that proponents of similar underwriting strategies came and went as quickly as a spring rainbow?

*President and CEO, Environmental Compliance Services, Inc. Exton, Pennsylvania. 
It is, of course, without question that the overall insurance market is quite different today than it was in the early 1980 's. In Europe at that time there was no environmental insurance market, and much of the contraction in the U.S. environmental insurance market in the early 80 's had nothing to do with environmental losses. But it is not clear if we have put behind us record catastrophic losses, depressed real estate values, environmental and asbestos losses, and the woes at Lloyds. In today's environment one cannot say with confidence that the outlook for long term stability in the property and casualty insurance market is better now than it was 12 years ago.

It is also without question that the technical side of environmental insurance underwriting has been aided by broader implementation of risk management techniques, that more insurance companies are utilizing underwriters with technical backgrounds, and that the science of environmental risk assessment has advanced significantly. However, the true question is, are these factors of sufficient merit to justify abandoning - or, in some quarters, not adopting - the rigorous underwriting criteria that helped separate the survivors from the fatalities in the U.S. market of the mid to late 1980's?

In the opinion of this observer, the answer is an unequivocal «No.» The underwriting of environmental liability was born of scientific analysis and realistic pricing. If today's underwriters think that they are now smart enough to do their job without these things, they will probably end up outsmarting themselves.

Only time will provide the final answer, and while we await the outcome, each buyer of environmental insurance must carefully survey the expanded field of providers. For the sweetness of a low price and minimal underwriting analysis may turn bitter if the chosen carrier disappears from the scene just when an insured's need for coverage is the greatest or, even worse, when a claim develops.

Set forth below in Section 2 is an outline of the environmental impairment liability (EIL) insurance coverages currently being offered by the major U.S. markets. Following that, Sections 3 and 4 describe the U.S. rating and engineering methodologies developed by ECS Underwriting and some other U.S. insurers. Finally, in Section 5, I offer my observations on the developing situation in Western Europe, as I understand it, and comment on the disquieting pricing and engineering practices that seem to be evolving in parts of that market. But the reader beware. The latter is a very fluid market. Some of my information may be dated even before it goes to press. Also, as primarily a U.S. and U.K. underwriter, my information on Continental markets may not be complete. I solicit the reader's input on this, and indeed on all aspects of this paper.

\section{Outline of available U.S. coverages}

In the U.S. there are a large number of insurers who offer some type of specialty EIL insurance. Some have only one or two product lines, or very low limits, or both. The markets and insurers listed in Figure 1 are the large players with meaningful limits and/or multi-line products. The numbers shown are per-occurrence capacities. Appendix A contains a further description of the various types of cover available in the U.S. today. 
Figure 1

\begin{tabular}{|c|c|c|c|c|c|c|}
\hline & $\begin{array}{l}\text { Pollution Legal } \\
\text { Liability } \\
\text { (Off-Site) }\end{array}$ & $\begin{array}{l}\text { Contractors } \\
\text { Pollution } \\
\text { Liability }\end{array}$ & $\begin{array}{l}\text { Consultants } \\
\text { Professional } \\
\text { Liability }\end{array}$ & $\begin{array}{l}\text { Consultants \& } \\
\text { Contractors } \\
\text { Combined }\end{array}$ & $\begin{array}{l}\text { On-Site } \\
\text { Liability }\end{array}$ & $\begin{array}{l}\text { Combined On } \\
\text { \& Off-Site }\end{array}$ \\
\hline $\begin{array}{l}\text { Commerce \& } \\
\text { Industry (AIG) }\end{array}$ & $\$ 40,000,000$ & $\$ 20,000,000$ & $\$ 20,000,000$ & $\$ 20,000,000$ & $\$ 40,000,000$ & \\
\hline $\begin{array}{l}\text { Reliance National } \\
\text { (thru ECS } \\
\text { Underwriting) }\end{array}$ & $\$ 30,000,000$ & $\$ 30,000,000$ & $\$ 30,000,000$ & $\$ 30,000,000$ & $\$ 30,000,000$ & $\$ 30,000,000$ \\
\hline Zurich America & $\$ 30,000,000$ & $\$ 10,000,000$ & $\$ 5,000,000$ & $\$ 5,000,000$ & $\$ 10,000,000$ & \\
\hline United Coastal & $\$ 7,000,000$ & $\$ 7,000,000$ & $\$ 7,000,000$ & $\$ 5,000,000$ & & \\
\hline General Star & & $\$ 3,000,000$ & $\$ 3,000,000$ & $\$ 3,000,000$ & & \\
\hline United Capital & & $\$ 5,000,000$ & & & & \\
\hline London & & & $\$ 15,000,000$ & & & \\
\hline CNA & & & $\$ 10,000,000$ & & $\$ 10,000,000$ & \\
\hline DPIC & & & $\$ 10,000,000$ & & & \\
\hline $\begin{array}{l}\text { Environmental } \\
\text { Warranty }\end{array}$ & & & & & $\$ 10,000,000$ & \\
\hline
\end{tabular}

\section{U.S. pricing}

The method of rating environmental risks, and hence of pricing them, is proprietary and variable with each insurer. Nevertheless, it appears that similar methodologies are employed by the major U.S. markets and variations are found principally in the weighting of factors and the degree of subjective evaluation permitted to or exercised by individual underwriters. The rating process described below is derived from the proprietary program developed by ECS Underwriting for pricing its PLL (third-party liability) coverage.

The process begins with the Evaluation Parameters set forth below. Note that item 4 is highly subjective and calls for a judgment on a scale of 1 to 5, with 1 being a low exposure location:

1. Account Name

2. Total Locations

3. Exposures

4. Underwriting Opinion

5. SIC Code

6. Sales

7. Base SIR 
The second step is to evaluate separately the following exposure factors, again on a scale of 1 to 5 :

\section{GRADUAL EXPOSURES}

8. Surrounding Environment

9. Current Site Use

10. Age of Facility

11. Effluent

12. Liquid Waste

13. Solid Waste

14. Air Emission/Controls

15. Tankage/Product Storage

16. Raw Materials

17. In-ground Features

18. Site History/Past Env'l Concerns

19. Env'l Practices/Regulatory Concerns

20. Env'l Sensitive Concerns/Receptors

\section{SUDDEN EXPOSURES}

21. Surrounding Environment

22. Current Site Use

23. Outside Influences

24. Liquid Material

25. Solid Material

26. Diking/Secondary Containment

27. Fire/Explosion Exposure

28. Fire/Explosion Response

29. Rupture/Leak Potential

30. Site History/Past Env'l Concerns

31. Env'l Practices/Regulatory Concerns

32. Air Emissions/Controls

In the next step the PLL rating program derives a base premium amount. The base premium amount corresponds with the following coverage terms:

- $\$ 1,000,000$ per Loss $\$ 1,000,000$ aggregate all Losses limit of liability

- $\$ 50,000$ Self Insured Retention

- A minimum possible premium of $\$ 10,000$

Premiums for additional insurance limits or greater retentions are derived by applying various multipliers to the rated base premium.

The base premium results from the following equation:

100* [Sales Factor + (Exposure Locations* (Location Factor/Total Number of Locations))]* SIC Code Factor* Opinion Factor* [Gradual Factor* $(1+$ Sudden/ Accidental Factor)]

Each of the factors in the equation, and in some cases each of several sub-factors, has been assigned a decimal value or weighting. These values are proprietary to ECS.

In other coverages, such as environmental consultants and contractors policies, additional factors must be considered. These include the education and the experience of key management and field personnel (technicians, engineers, etc.) and the type and volume of services provided (e.g., environmental, remediation, industrial hygiene, geotechnical, etc.). Also considered are the nature of the contaminants encountered in providing such services, the firm's age, loss and business experience, extent of its subcontracting and the liability terms (or lack of same) contained in its standard forms of client contracts. Other important factors are a firm's accident contingency plans, employee environmental training programs and site-safety protocols. These and other factors are then evaluated and rated in accordance with the methodology described above. 


\section{U.S. engineering}

The following discussion of U.S. environmental risk engineering is based upon practices in force at ECS Underwriting. Similar practices, at least in theory, are followed by the other major U.S. providers of EIL insurance.

At ECS Underwriting, frequent, in-depth engineering risk assessments are the foundation of ECS' underwriting methodology and loss control program. ECS requires that all facilities undergo a comprehensive assessment of their operational risks PRIOR to binding coverage. Alternatively, in a narrow band of «low-exposure» accounts, the underwriter may waive engineering prior to binding if sufficient information is supplied with the application. However, even in such a case, continuation of coverage is contingent upon satisfactory completion of an engineering survey within 30 days of binding.

ECS Underwriting risk assessment surveys are performed by highly qualified and specially trained personnel employed by CSI, an ECS Underwriting affiliate. CSI's technical personnel include geologists, hydrogeologists, industrial hygienists and chemical engineers, among others. After the survey, these risk assessment professionals work closely with the underwriters to analyze and evaluate the data produced by the survey and to assist the underwriters in reaching the underwriting decision.

CSI employs only highly skilled technical personnel and then invests heavily in their education and training as environmental risk assessors. ECS Underwriting believes that such stringent methods are essential to produce assessments that accurately reveal the complex and highly technical nature of environmental risks. The danger of utilizing inadequate personnel in this task is amply demonstrated by the difficulties that befell the many U.S. insurance companies that quickly entered and even more quickly abandoned the environmental market in the 1980's. These companies failed to understand the nature of environmental risks - and hence failed to quantify them accurately - and were driven from the field by significant unanticipated losses.

The loss control engineer tailors the assessments to the exposures presented by the operations and the type of liability coverage sought (e.g., off-site, on-side, professional, etc.). The assessment begins with the loss control engineer reviewing the underwriter's files for pertinent data and documents submitted by the insured in support of its application. This file review minimizes duplication of documentation and provides the engineer with a good knowledge of the insured's operations prior to making contact with the insured.

The loss control engineer also meets with the underwriter at this time to address coverage issues and particular areas of concern that the underwriter may identify. For example, the underwriter may have concerns about the qualifications and experience of operating personnel or the general conditions at a site. The underwriter may also ask the loss control engineer to visit other sites of the insured with a view to expanding coverage in the future.

The initial engineering assessment is a rigorous investigation of a facility, its management, history, operations and exposures. An outline of a typical facility report is shown in Figure 2 . The survey analyzes the gradual/non-accidental and sudden/accidental exposures at the site to allow the underwriter to refine his/her preliminary evaluation of the site and rate it appropriately. 
One, sometimes two, representatives from the loss control engineering firm visit the site for between 3 and 8 hours. Interviews are held with key management personnel, which may include facility managers; environmental managers, engineers or coordinators; health and safety directors, managers or coordinators; operations managers or foremen; and corporate risk management personnel. In addition to interviews, the engineer reviews and obtains copies of relevant documentation, including operating permits and related inspection reports; waste acceptance plans; facility plans and process flow diagrams; analytical results from sampling of groundwater, soil, air emissions, wastewater discharges, etc.; and management and contingency plans including Spill Containment, Countermeasures, and Control (SPCC) Plans, Personnel Training Programs, and Standard Operating Procedures.

\section{Figure 2 - Report Outline}

The survey initially focuses on the experience and qualifications of personnel mana-

\section{CORPORATE ORGANIZATION \\ Company Profile \\ Environmental Management}

\section{FACILITY DESCRIPTION}

Site Location and Layout

Site History and Ownership

Facility Personnel

\section{ENVIRONMENTAL SETTING AND PATHWAYS}

Surrounding Land Use and Population

Topography

Surface Water

Geology and Hydrogeology

Climate

\section{ENVIRONMENTAL HAZARDS}

Potential for Contamination of Soil and Groundwater

Potential for Contamination of Surface Water

Potential for Air Emissions

Polychlorinated Biphenyls

Asbestos

Lead

\section{OPERATIONS AND PROCESSES}

Permit Status

Facility Operations

Raw Material

Products

Waste Management

On-site Tanks

Stormwater Management

Utilities

\section{ENVIRONMENTAL RISK} MANAGEMENT

Spill Prevention and Contingency Plans

Personnel Training and Safety Programs

Site Security

Fire Prevention/Suppression Systems

Housekeeping
REGULATORY AGENCY CONTACTS 
ging and operating the facility. The loss control engineer also examines the qualifications, experience, and training of personnel responsible for the environmental affairs at a facility. Particular attention is devoted to any past regulatory violations and to how individuals stay abreast of changing regulations that impact the facility. Coverage has been denied in cases where underwriters were not comfortable with the methods employed by the prospective insured's operating personnel.

The engineering survey next examines general background information on the site, including specific location, ownership and past history. Frequently, this investigation identifies other locations of the insured that may require coverage, or reveals off-site material storage which, although not specifically covered, may generate defense costs if the insured files a claim for losses stemming from such off-site operations.

The survey next focuses on specific operations conducted at the site. The loss control engineer obtains a thorough understanding of the operations and how the insured performs them, so that he/she may identify the location of potential failure points leading to environmental impairment. The engineer asks questions to determine all final and intermediate products associated with the operations, as well as all raw materials, and to assess the potential hazards associated with materials handling. The engineer and insured discuss handling and storage provisions, including storage tank installation dates, maintenance records, integrity testing intervals and results, and protection systems. The loss control engineer also looks to see if incompatible materials are segregated while in storage, to prevent intermingling in an accident which could increase the magnitude or probability of a loss. The engineer also investigates stormwater drainage patterns and control systems.

Another loss exposure reviewed by the engineer is the probability of a loss occurring from sabotage and vandalism. The loss control engineer will observe security measures at the site and may recommend security fencing if not already in place. Facilities located in areas with a high incidence of vandalism may require more sophisticated security and alarm systems. Valves on sensitive process equipment and discharges from secondary containment structures (which may collect contaminated stormwater) should be provided with locks to prevent unauthorized operation.

The assessment also addresses the environmental risk management programs and supporting documentation. Typical programs developed by facilities include spill response plans, emergency contingency plans, personnel protective equipment training, standard operating procedures, and personnel safety programs. The loss control engineer obtains and reviews copies of these documents, and during the course of a visual inspection of the facility attempts to determine the level of compliance with these programs. The assessor may also request documentation to support the claim that personnel are trained on topics at specific time intervals.

The final portion of the survey is a visual inspection of the operations at the site. This provides an opportunity for the loss control engineer to verify the implementation of the loss control programs detailed in the interview portion of the assessment. The engineer will inspect the integrity of storage tanks and secondary containment structures; look for distressed vegetation, stained soils, or signs of process equipment leaks; assess the level of housekeeping; verify that personnel are using necessary protective equipment; identify the presence of odors that may migrate off site; view the air and waste water discharge 
streams; and look for other shortcomings in the implementation of loss control programs. In the final analysis, it is the actual level of program implementation, which cannot be determined from the underwriter's desk, that determines the outcome of the assessment, not the level of documentation provided.

The site assessment concludes with a discussion of the preliminary areas of concern identified by the loss control engineer. This gives the insured an opportunity to clarify issues of concern prior to the preparation of recommendations by the engineer. The engineer may also request that additional documentation be forwarded to his/her office for further review.

After the site assessment, the loss control engineer meets with the underwriter of the account to review the preliminary findings. At this time the underwriter has an opportunity to reevaluate his/her underwriting decisions. The interactive nature of this meeting also provides the underwriter with an opportunity to probe particular areas of concern and develop general impressions that are sometimes difficult to communicate in writing.

Finally, the engineer produces a written loss control report, which will normally include loss control recommendations for the insured. The engineer then contacts regulatory agencies that inspect the facility, or are otherwise involved with the facility through permitting, consent agreements or closure operations, in order to obtain independent confirmation of the regulatory status of the facility. These contacts may also yield insights into the approach of facility management to regulatory compliance, for example, proactive compliance above and beyond the regulations versus compliance only when issued with a notice of violation from an agency.

\section{EIL Insurance in Europe}

With two exceptions, no significant, multi-line EIL insurance market has yet developed in the countries of the EU. The first exception is the U.K. where, on a modest scale, ECS and AIG offer a range of EIL products, including first and third party liability and consultants and contractors professional liability policies. Some other U.K. insurers (e.g., Lloyds and Sun Alliance) offer a third-party pollution liability policy. A second exception is Germany, where a number of private insurers offer third-party pollution liability policies. Elsewhere on the Continent, the EIL market, such as it is, is comprised principally of the various national pollution pools. There are at least five such pools* :

Pool
MAS
Assurpol
Inquinamento
Danpool
PEC

Country
The Netherlands
France
Italy
Denmark
Spain

* Apparently there is also an EIL «facility» pool in Sweden but the author lacks sufficient information to address it in this paper. 
Figure 3 shows the stated capacity for each pool and its reported 1993 pollution premium volume.

Figure 3

\begin{tabular}{|cccc|}
\hline Pool & $\begin{array}{c}\text { Capacity in } \\
\text { Home Currency }\end{array}$ & $\begin{array}{c}\text { Capacity in } \\
\text { U.S. \$ }\end{array}$ & 1993 Premium \\
MAS & NLG $17.3 \mathrm{~m}$ & $10 \mathrm{~m}$ & NLG $6.1 \mathrm{~m}$ \\
Assurpol & FF $192 \mathrm{~m}$ & $48 \mathrm{~m}$ & FF $27 \mathrm{~m}$ \\
Inquin & Li $50,000 \mathrm{~m}$ & $32 \mathrm{~m}$ & Li $7,850 \mathrm{~m}$ \\
Danpool & Dkr $61 \mathrm{~m}$ & $2 \mathrm{~m} / 10 \mathrm{~m}$ & negligible \\
PEC & Ptas 560m & $5 \mathrm{~m}$ & [none yet-still in \\
& & & formation] \\
\hline
\end{tabular}

Information from various public and private sources suggests to this observer that the pricing policies of the major pools are inadequate. Granted that Western Europe does not (at least not yet) suffer from the scourge of excessive litigation, jury awards and Superfund liabilities that characterize the U.S. marketplace. But one would still assume that the value of damages to third parties and the costs of pollution clean-up cannot be significantly less in the EU than in the U.S. Moreover, broad-based clean-up liability for pollution damage, both off-site (third party) and on-site (first party), will surely be a feature of the EU landscape in the years ahead. One cannot predict whether this will occur through an EU Directive utilizing the polluter-pays principles set forth in the Commission's 1993 Green Paper and the civil liability studies now underway on behalf of DGXI, through wholesale adoption by EU countries of the Council of Europe's Convention on Civil Liability for Damage Resulting from Activities Dangerous to the Environment, or through country-bycountry legislation similar to the Dutch Soil Protection Act. But it seems very likely that a broad-based regime of civil liability for environmental damage will appear in the EU in one way or another in the near future.

Therefore, future EIL coverage requirements and anticipated loss levels in the EU should be approximately the same as in the U.S. The result should be that pricing of policies should also be about the same, with the usual adjustments for cultural differences, level of competition and national legal requirements.

It does not appear, however, that this is the current operating premise among the major national pools. For example, Assurpol realized approximately FF $28 \mathrm{~m}$ of gross premium in 1993 from approximately 400 insureds. This means that the average policy premium was FF 70,000 , or about $\$ 14,000$. That this pricing level is inadequate is amply demonstrated by Assurpol's 1993 results: losses of FF $27 \mathrm{~m}$ - resulting in a pure loss ratio of $96 \%$ from just four paid claims! Four losses out of 400 insureds is $1 \%$ of the number of insureds. In our experience, a $1 \%$ loss incidence rate is quite low. Anything close to a «normal» loss incidence rate in 1993 would have put Assurpol solidly in an underwriting loss position. And a few large losses could have tested its solvency on a stand-alone basis (i.e., without considering any guarantees or back-ups from its members). 
Pricing by the MAS pool appears to follow a similar line. MAS' total gross premium in 1993 was Dfl 6,112,000 from approximately 1800 insureds. Thus, the average policy premium was Dfl 3,400 , or about $\$ 2,000$. The size of policy premiums obviously will vary with the amount of coverage extended, but even assuming that the typical MAS policy has very low limits (an assumption that is premised on the fact that the MAS book is comprised predominantly of small firms and agricultural risks), a $\$ 2,000$ average premium per policy seems very low. $\$ 2,000$ is less than the cost of a good environmental site assessment! To be sure, MAS' underwriting results have been positive, but this appears due to some legal liability uncertainty in The Netherlands and a run of good fortune rather than adequate pricing. Even the MAS Board points out in its 1993 Annual Report that «a small number of large claims may make the overall picture quite different. In addition, as the environmental portfolio grows older, the risk is getting larger. The claims burden is likely to increase due to this 'aging risk.'»

To comment accurately on the engineering practices of the pools and other European EIL insurers is a risky undertaking because of a lack of inside information about the true nature of those practices. All underwriters are naturally inclined to say that their underwriting methodologies are adequate and proper for the risks involved. One can only speculate, therefore, about what happens in reality, but one senses that the stated policy of rigorous site assessments and technical underwriting is not the actual practice.

This sense is based upon some highly suggestive though admittedly indirect evidence. First, the seemingly inadequate level of pricing suggests that serious engineering is lacking because the premiums do not seem to be large enough on average to permit a high level of engineering. Second, conversations with underwriters and insurers who purport to be familiar with the operations of some of the pools suggest that, in actual practice, site assessments are precursory or absent and that most EIL underwriting is done from the insured's application, supporting documentation and certain «desk materials.» In addition, outside of the pools, there is evidence that some EU insurers now testing the EIL waters are pricing cover on the basis of a pre-set percentage of the coverage limits, with little or no attempt at technical underwriting.

\section{Conclusion}

As an underwriter who «survived» the rout of the U.S. environmental insurance market in the 1980's, I am disturbed by the trends I see developing now in the U.S. and in at least some portions of the EIL insurance market in the EU. If my observations are correct, both EIL insurance markets are wandering from the straight road of rigorous review and comprehensive site assessments in the underwriting of environmental risks.

A recent analysis by A.M. Best Co., Inc. states that the net present value of the U.S. insurance industry's exposure to environmental and asbestos claims over the next 25 years is in the neighborhood of $\$ 132$ billion. This number represents $72 \%$ of the industry's current capital and surplus! Much of this burden will fall on insurers who long ago abandoned the environmental market after belatedly realizing that their underwriting methodologies were inadequate for the task.

But that was a decade ago ... and memories are short. I have the uneasy feeling that inadequate environmental underwriting is again rearing its ugly head in the U.S. and gai- 
ning a foothold in the emerging EIL market in the EU. I caution our industry against such complacency and I suggest to you that, as underwriters, we must carefully consider the warning, "Those who do not learn from the past are condemned to repeat it.»

\section{APPENDIX A}

\section{Pollution Legal Liability Coverage}

This policy provides cover for third party legal liability for fixed sites and is generically known as Pollution Legal Liability. Coverage is available for any fixed site with the potential to cause off site bodily injury or property damage resulting from sudden accidental and/or gradual pollution releases. This policy, like all of the other environmental policies to be described in the following paragraphs, is currently only available on a claims made basis, with defense costs provided within the stated limits. Despite a trend toward reduced reliance upon detailed risk assessment reports, most underwriters still require some scientific documentation of the potential pollution exposure.

\section{Contractors Pollution Liability Coverage}

This product provides coverage for firms involved in the business of cleaning up contaminated sites and is generally referred to as Contractors Pollution Liability.

This market now encompasses all contractors who could create or exacerbate a pollution condition, such as sewer contractors, road pavers, industrial maintenance firms, painting contractors, etc. Although requiring an increased level of underwriting, this coverage is also available for firms performing remediation projects at Superfund sites, as well as sites falling under the control of the Department of Defense and the Department of Energy. It is also now possible to obtain this coverage for a specific project lasting several years or on an annual basis, providing blanket coverage for designated operations. Many insurers will also provide completed operation coverage extensions. Most carriers will not require any physical risk assessment of the contractor applicant prior to binding. However, at least one insurer, the Reliance National, which provides coverage through ECS Underwriting (an independent underwriting manager specializing in environmental insurance), will require a corporate review, and at least one on-site risk assessment to be performed at the insurer's cost, after binding coverage.

\section{Consultants Professional Liability Coverage}

This product provides professional liability cover for consultants who analyze contaminated sites and recommend remediation plans.

The market for architects and engineers professional liability had to react to the fact that many of such firms added environmental studies to their portfolio of professional services. The result being that today most architect and engineer underwriters will provide serious levels of environmental liability coverage, but one should carefully review the policy form as there are wide disparities in coverage. 


\section{Combined Consultants/Contractor Coverage}

As the business of evaluating and cleaning up contaminated sites grew, the providers of these services saw opportunities in combining both ends of the process, thus providing clients with one-stop shopping. These firms possessed a competitive edge, but also faced increased types of environmental liability exposures. And often there was no bright line separating these exposures.

In response, the environmental insurance market created a new policy which, under one set of general conditions, provides coverage for both professional liability and contractors liability. This new policy is titled differently by each of the following markets, with Commerce and Industry referring to theirs as C.O.P.S. and ECS Underwriting calling their combined policy C.E.L.

\section{On-Site Coverage}

In today's legal environment in the U.S. most on-site contamination must be remediated, even in the absence of a third party claim. The underwriting of on-site clean-up coverage presents several difficult challenges, such as how to avoid providing maintenance coverage, how clean is clean, and what should be the trigger for coverage. Yet underwriters have created policies which will provide funds for the remediation of contaminated property owned or controlled by the insured.

The demand for this coverage in the U.S. was significantly increased when the net of Superfund liability was cast far enough to include almost anyone who had anything to do with a particular parcel of land, including developers, lenders, and estate trustees.

The wording of the insuring agreement, exclusions and targeted insureds sought by the offering carriers vary considerably, so careful examination of their capabilities and appetite for risk are in order.

\section{Combined On and Off Site Coverage}

Accounts whose operations present both an on-site and off-site environmental liability risk present underwriters with such levels of risk or historical contamination that they are usually unwilling to provide on-site coverage in addition to a third party policy. In some cases, however, the providers of both the third party and first party clean-up coverage may be willing to write both policies for one account, at a cost less than that of buying these coverages separately. One carrier, the Reliance National, through ECS Underwriting, has developed a combined policy which provides on-site clean-up coverage and third party legal liability under one form. This new coverage is called the Pollution and Remediation Legal Liability policy, and is available at per occurrence limits up to $\$ 25,000,000$. It is believed that this approach will become generally accepted for accounts not presenting underwriters with significant exposures. 